\title{
AKEDIA \\ O IMPACTO ECONÔMICO NAS MICROEMPRESAS BRASILEIRAS DURANTE A CRISE DA COVID-19 E AS MEDIDAS ADOTADAS POR PARTE DO GOVERNO FEDERAL NO MERCADO DE TRABALHO
}

\author{
English title: THE ECONOMIC IMPACT ON BRAZILIAN MICRO ENTERPRISES \\ DURING THE CRISIS OF COVID-19 AND THE MEASURES ADOPTED \\ BY THE FEDERAL GOVERNMENT IN THE LABOR MARKET
}

\section{doi>10.33726/akdpapers2447-7656v11a72021p58-78}

\author{
MENDES, Daniel da Silva ${ }^{1}$ - daniel.1028710@discente.uemg.br \\ PEDROSO FILHO, José ${ }^{2}$ - jose.1001720@discente.uemg.br \\ FREITAS SILVA, Josney ${ }^{3}$ - (D) https://orcid.org/ 0000-0002-9349-4497
}

\begin{abstract}
RESUMO: Este paper tem por objetivo abordar o impacto econômico durante a crise sanitária e econômica do COVID-19, nas microempresas brasileiras levantadas pelo SEBRAE, bem como, entender quais medidas foram adotadas pelo Governo Federal e o Ministério da Economia para a diminuição desse choque, no contexto do mercado de trabalho. Metodologicamente, usamos o método indutivo, lançando mão do procedimento de apresentar alguns dados capazes de amostrar a dimensão da conjuntura atual, combinados com uma pesquisa quantitativa aplicada pelo SEBRAE / FGV, estudo no qual se percebem as consequências da COVID-19 para a operação das microempresas. Como parte dos resultados de nossa investigação, vê-se que o agravo da situação atual seria mais facilmente contornável, caso a maioria da população estivesse ocupada em empregos formais e tivesse uma estabilidade financeira diferente da realidade que o país vive.
\end{abstract}

PALAVRAS-CHAVE: Microempresas, COVID-19, Governo Federal, Impactos econômicos

ABSTRACT: This paper aims to address the economic impact during the health and economic crisis of COVID-19, in the Brazilian micro-enterprises raised by SEBRAE, as well as to understand what measures were adopted by the Federal Government and the Ministry of Economy to reduce this shock, in the context of the labor market. Methodologically, we use the inductive method, using the procedure of presenting some data capable of sampling the dimension of the current situation, combined with a quantitative research applied by SEBRAE / FGV, a study in which the consequences of COVID-19 for the operation of micro-enterprises. As part of the results of our investigation, we see that the aggravation of the current situation would be more easily overcome, if the majority of the population were engaged in formal jobs and had a financial stability different from the reality that the country is experiencing.

KEYWORDS: Microenterprises, COVID-19, Federal Government, Economic impacts

\footnotetext{
${ }^{1}$ Estudante de graduação do Curso de Bacharelado em Administração, da Universidade do Estado de Minas Gerais (UEMG - Unidade de Frutal).

${ }^{2}$ Estudante de graduação do Curso de Bacharelado em Administração, da Universidade do Estado de Minas Gerais (UEMG - Unidade de Frutal).

${ }^{3}$ Doutor em Ensino de Ciências e Matemática. Mestre em Ensino de Ciências. Especialista em Gestão de Pequenas e Médias Empresas. Especialista em Gestão Empresarial Estratégica. Licenciado em Matemática e Pedagogia. Professor efetivo na Universidade do Estado de Minas Gerais - UEMG Unidade Frutal/MG. E-mail: josney.silva@uemg.br.
} 


\section{INTRODUÇÃO}

A Pandemia da COVID-19 gerou uma crise sanitária que desestabilizou a sociedade em escala mundial. Além de uma crise sanitária causada pela disseminação do vírus SARS-CoV-2, também conhecido por Coronavírus, a disseminação da doença afetou a economia de forma significativa e trouxe severas consequências, principalmente para Microempresas e Empresas de Pequeno Porte, nas quais os proprietários e funcionários dependem do seu funcionamento para sua subsistência.

Alguns fatores como o desemprego, a instabilidade laboral e empresarial estão presentes na conjuntura da Pandemia, tendo em conta que a grande maioria dos empregos se encontra no setor privado. De acordo com Mota (2020), a Pandemia da COVID-19 está desencadeando a maior crise já vista no mercado de trabalho, desde a Segunda Guerra Mundial, o que, per se, justifica uma pesquisa sobre este tema:

Quase 38\% da força de trabalho no planeta, o equivalente a 1,25 bilhão de pessoas, está empregada em setores duramente afetados pela paralisação das atividades em diversos setores, segundo a estimativa mais recente da Organização Internacional do Trabalho (OIT), e correm o risco de ficar sem trabalho nos próximos meses (MOTA, 2020, s/p.).

Neste cenário, é natural que surja o interesse em investigar quais os impactos econômicos, sociais, políticos que na Pandemia de COVID-19 podem ser identificados no âmbito das Microempresas e Empresas de Pequeno Porte no Brasil.

O objetivo geral desta pesquisa consiste em conhecer os impactos econômicos da Pandemia da COVID-19 no ambiente das Microempresas e Empresas de Pequeno Porte no país e identificar como as empresas na área de Serviços de Alimentação, no município de Frutal, Minas Gerais, se adaptaram à nova realidade imposta pelos protocolos exigidos para 0 enfrentamento da Pandemia.

Para tanto, apresentam-se como objetivos específicos: descrever os resultados de uma pesquisa realizada por uma parceria entre a Fundação Getúlio Vargas (FGV) e o Serviço Nacional de Apoio às Micro e Pequenas Empresas (SEBRAE), que tratou do impacto da Pandemia de Coronavírus nos 


\section{AKED更A}

Pequenos Negócios; compreender a relação entre os reveses econômicos e as medidas governamentais adotadas por parte do Governo Federal para a diminuição da crise econômica. Atrelados a estes objetivos, temos ainda interesse quanto aos aportes de estatísticas sobre o mercado de trabalho, que deem conta da compreensão da importância das microempresas para a economia em nível nacional; identificar, por meio de um levantamento, quais empresas da área de Serviços de Alimentação, utilizam estratégias para driblar a crise econômica advinda da Pandemia.

Quanto aos aspectos metodológicos, esta pesquisa classifica-se como pesquisa aplicada, por procurar produzir conhecimentos que permitirão a aplicação prática para solução de problemas específicos. Quanto ao método científico, utilizou-se $o$ indutivo, em que $o$ argumento passa do particular para $o$ geral, a partir de generalizações que derivam de observações de casos da realidade concreta. Quanto ao objetivo do estudo, esta pesquisa classifica-se como descritiva, ao expor características de uma determinada população, por meio de dados coletados junto a uma amostra, demandando técnicas padronizadas. Como procedimentos técnicos utilizados, destacam-se a pesquisa bibliográfica e a pesquisa documental em documentos secundários (PRODANOV; FREITAS, 2013).

\section{MICROEMPRESAS E EMPRESAS DE PEQUENO PORTE}

A Lei Geral das Microempresas e Empresas de Pequeno Porte (Lei Complementar no. 123/2006) foi instituída em 2006 para regulamentar 0 disposto na Constituição Federal Brasileira, que previa um tratamento diferenciado e favorável a esta classe de empresas, face à importância do segmento para o cenário econômico nacional.

Esta Lei já passou por quatro alterações, desde que foi criada, mas manteve o objetivo de contribuir para o desenvolvimento e a competitividade das microempresas e empresas de pequeno porte brasileiras, com 0 desenvolvimento de estratégia de geração de emprego, distribuição de renda, inclusão social, redução da informalidade e fortalecimento da economia. 
Por meio desta Lei, também foi instituído um regime tributário específico para os pequenos negócios, que garante redução da carga de impostos e simplificação dos processos de cálculo e recolhimento, denominado Simples Nacional (SEBRAE, 2021).

A Lei Geral estabelece três tipos de pequenos negócios, classificados pelo critério da receita bruta anual, sendo elas a Microempresa, a Empresa de Pequeno Porte e o Microempreendedor Individual. As diferenças entre cada uma delas e o critério da receita bruta anual encontram-se no Quadro 1.

Quadro 1 - Diferenças entre Microempresa, Empresa de Pequeno Porte e Microempreendedor Individual

\begin{tabular}{|l|l|l|}
\hline Classificação & Definição & Receita Bruta Anual \\
\hline Microempresa & $\begin{array}{l}\text { Sociedade empresária, sociedade } \\
\text { simples, empresa individual de } \\
\text { responsabilidade limitada e o } \\
\text { empresário, devidamente registrados } \\
\text { nos órgãos competentes, que aufira } \\
\text { em cada ano calendário. }\end{array}$ & $\begin{array}{l}\text { Igual ou inferior a } \mathrm{R} \$ \\
360.000,00 .\end{array}$ \\
\hline $\begin{array}{l}\text { Empresa de Pequeno } \\
\text { Porte }\end{array}$ & $\begin{array}{l}\text { A empresa de pequeno porte não } \\
\text { perderá o seu enquadramento se obter } \\
\text { adicionais de receitas de exportação } \\
\text { até o limite de } \mathrm{R} \$ 4.800 .000,00 \text {. }\end{array}$ & $\begin{array}{l}\text { Superior a } \mathrm{R} \$ 360.000,00 \\
\text { e igual ou inferior a } \mathrm{R} \$ \\
4.800 .000,00\end{array}$ \\
\hline $\begin{array}{l}\text { Microempreendedor } \\
\text { Individual }\end{array}$ & $\begin{array}{l}\text { E a pessoa que trabalha por conta } \\
\text { própria e se legaliza como pequeno } \\
\text { empresário optante pelo Simples } \\
\text { Nacional. O microempreendedor pode } \\
\text { possuir um único empregado e não } \\
\text { pode ser sócio ou titular de outra } \\
\text { empresa. }\end{array}$ & $\begin{array}{l}\text { Igual ou inferior a } \mathrm{R} \$ \\
81.000,00\end{array}$ \\
\hline
\end{tabular}

Fonte: SEBRAE, 2021

O Ministério da Economia, por meio da Secretaria Especial de Produtividade, Emprego e Competitividade (SEPEC/ME) destaca que as Microempresas e Empresas de Pequeno Porte, juntas, representam 99\% dos negócios brasileiros, respondendo por $30 \%$ de tudo que é produzido no Brasil, sendo ainda responsáveis por $55 \%$ dos empregos gerados no país (BRASIL, 2020b).

De acordo com o SEBRAE (2020b), as Micro e Pequenas Empresas (MPE), nas últimas três décadas, vêm desempenhando um papel cada vez mais estratégico na economia brasileira, alcançando $30 \%$ do valor adicionado ao PIB (Produto Interno Bruto) do país.

Segundo aponta o estudo "Participação das MPE na economia nacional e regional", elaborado pelo SEBRAE e a Fundação Getúlio Vargas (FGV), 


\section{AKEDIA}

existe um movimento consistente e crescente sobre a importância dos pequenos negócios na geração de empregos e arrecadação de impostos, que se estende desde 1985, quando a participação das MPE alcançou $21 \%$ do PIB.

Particularmente, sobre a geração de empregos, de 2006 a 2019, as MPEs apresentaram um saldo positivo, respondendo pela criação de cerca de 13,5 milhões de empregos, enquanto as grandes empresas fecharam cerca de 1,1 milhão de postos de trabalho, no mesmo período.

As MPEs são responsáveis por mais da metade dos empregos formais do país, representando um importante efeito amortecedor em momentos de crise, tal como o atual, uma vez que são menos propensas a demitir seus colaboradores. Considera-se também que esses empregos se concentram nas atividades de Comércio e de Serviços. Em 2017, as MPEs representavam 66\% dos empregos no Comércio, $48 \%$ nos Serviços e $43 \%$ na Indústria (SEBRAE; FGV, 2020). É inegável a importância deste segmento empresarial ao equilíbrio socioeconômico nacional. Portanto, é imprescindível entender como a crise sanitária influencia as MPEs e como elas atuam na busca de soluções e alternativas para o enfrentamento desta Pandemia.

\section{O IMPACTO DA PANDEMIA SOBRE AS MICROEMPRESAS E EMPRESAS DE PEQUENO PORTE}

Segundo Silber (2020), a Pandemia da COVID-19 teve início, a partir de dezembro de 2019, na China. Em todas as regiões do mundo, a primeira alternativa de proteção foi o uso do isolamento social, com o intuito de achatar a curva de contágio e diminuir o colapso simultâneo dos mercados pela paralização da produção de bens e serviços, queda da demanda agregada e crise do crédito. Contudo, esse remédio gerou uma parada súbita na economia mundial, que só pode ser comparada com a Grande Depressão dos anos 1930.

Silber (2020) complementa ainda, dizendo que a literatura empírica sobre grandes pandemias indica que os países que adotaram estratégias de distanciamento mais radicais tiveram uma recuperação econômica mais rápida, a exemplo da crise espanhola de 1918-1920.

Foi assim, então, que pesquisadores da área de saúde e da economia firmaram como estratégia mais adequada, o isolamento social, acompanhado 


\section{AKED霆}

da testagem do máximo de casos suspeitos para diminuir o ritmo do contágio exponencial e possibilitar a retomada da atividade econômica quando o número de contaminados e de mortes cedesse.

Na Pandemia atual, os casos mais bem-sucedidos foram os do Uruguai, da República Dominicana, de Barbados, do Camboja, da Tailândia, da Austrália, da Nova-Zelândia, da Islândia, da Croácia e de Montenegro, os quais tiveram pequenos impactos na economia e um pequeno número de contaminados e mortes ao seguirem estes protocolos.

De acordo com Mattei e Heinen (2020), a crise econômica que já deixava sinais de alerta ao sistema econômico global, apenas se amplificou com o processo de conversão da epidemia de COVID-19 numa Pandemia.

A chegada desta nova crise, no Brasil, foi ainda mais grave, em virtude de que a economia do país, além de não ter se recuperado da grande recessão ocorrida entre os anos de 2015 e 2017, apresentou modestos sinais de retomada em 2018 e 2019. Assim, os impactos da crise provocada pela COVID-19 na economia nacional, em 2020, vieram a se somar a um quadro socioeconômico que já caminhava rumo a uma incontestável degradação.

Conforme apresenta Silber (2020), os solavancos da Pandemia para a economia brasileira estão sendo radicais, justamente em função do seu baixo dinamismo, que vem se arrastando desde o início dos anos 1980, com um catastrófico agravante adicional: em 2015-2016, o país passou por uma recessão profunda e, em 2015-2016, quando o PIB teve uma queda cumulativa de $6,7 \%$ e, em termos per capta, o recuo registrado foi de $8,3 \%$.

Como era de se esperar, essas crises aumentaram significativamente a informalidade no mercado de trabalho, atingindo $48 \%$ da população já em meados de 2020. Mattei e Heinen (2020) corroboram ao apresentar que o reduzido grau de formalização agrava os efeitos da COVID-19 sobre o mercado de trabalho. O nível de formalidade das ocupações no Brasil era de 55,2\%, em 2014 e, em 2016, manteve-se próximo a esse patamar. O emprego formal passou a cair aceleradamente, desde então, atingindo seu menor patamar em 2020, quando apenas $52,1 \%$ dos brasileiros encontravam-se em ocupações formais. 


\section{AKEDIA}

Neste sentido, de 2014 em diante, o mercado de trabalho no país perdeu 2,5 milhões de empregos com carteira de trabalho assinada. Como resultado desse processo, temos a queda da participação dessa categoria no agregado geral, para $37,2 \%$ no trimestre, com fim em fevereiro de 2020 . Com isso, parte dessa população desempregada se viu obrigada a assumir ocupações informais. Assim, os trabalhadores, por conta própria, passaram de $23,2 \%$ em 2014 , para $26,1 \%$ do total de ocupados, em 2020, o que significou um crescimento absoluto de $2,5 \%$ ao ano.

Há que se considerar, mesmo que de forma menos intensa, que os empregados sem carteira de trabalho assinada cresceram $1,6 \%$ ao ano em termos absolutos, e 0,8\%, em termos relativos, atingindo $13,7 \%$ das ocupações totais em 2020.

\section{ASPECTOS METODOLÓGICOS}

Para conhecer os impactos da Pandemia de COVID-19 no ambiente das Microempresas e Empresas de Pequeno Porte no país, optou-se pela realização de uma pesquisa documental, que, segundo Severino (2007), é aquela que se utiliza de fontes documentais, no sentido amplo, isto é, não só documentos impressos, mas, também, outros tipos de documentos, tais como jornais, fotos, filmes, gravações, documentos legais.

Para tanto, fez-se o uso de uma pesquisa realizada pela parceria entre a Fundação Getúlio Vargas (FGV) e o Serviço Nacional de Apoio às Micro e Pequenas Empresas (SEBRAE) sobre o impacto da Pandemia de Coronavírus nos Pequenos Negócios, em sua $9^{a}$ edição, e de um levantamento das empresas que estão presentes nos aplicativos iFood e UaiRango. E, a partir delas, verificar quais mantém perfis no Instagram, com o intuito de identificar como as empresas na área de Serviços de Alimentação, no município de Frutal, Minas Gerais, se adaptaram à nova realidade imposta pelos protocolos exigidos para o enfrentamento da Pandemia. Neste levantamento foram identificadas 111 empresas que possuem perfis no iFood e no UaiRango, na cidade de Frutal - MG.

O documento intitulado "O impacto da pandemia de Coronavírus nos Pequenos Negócios - 9a edição" é uma pesquisa qualitativa, realizada por 
meio de um formulário online (web survey), entre os dias 20/11/2020 a 24/11/2020, mas que também apresenta resultados desde a $1^{\text {a }}$ edição, realizada entre 19/03/2020 e 23/02/2020.

Parte de um universo de 17,2 milhões de pequenos negócios, constituindo uma amostra com 6.138 respondentes de todos os 26 Estados e Distrito Federal, composta por 57\% de Microempreendedores Individuais (MEI), $38 \%$ de Microempresas (ME) e 5\% de Empresas de Pequeno Porte (EPP).

O erro amostral é de $+/-1 \%$, com intervalo de confiança de $95 \%$. Os resultados são ponderados por Unidade Federativa e por porte, levando em conta o universo das Micro e Pequenas Empresas.

\section{MUDANÇAS DE FUNCIONAMENTO}

O primeiro impacto percebido pelas empresas, motivado pela Pandemia de COVID-19 foi a restrição de circulação de pessoas, o isolamento social. Ao longo do período que se estende desde maio de 2020, quando da 4⿳亠丷a edição da pesquisa realizada pela parceria entre SEBRAE e FVG, houve o questionamento sobre como estaria a restrição de pessoas no município naquele momento (Figura 1). As respostas possíveis eram quatro: quarentena (fechamento parcial); Lockdown (fechamento total); em processo de reabertura/aberto; e, não teve restrição.

Percebe-se que a Quarentena iniciou com 57\% das empresas pesquisadas na $4^{\mathrm{a}}$ edição, diminuindo para $10 \%$ na $8^{\mathrm{a}}$ edição e voltando a subir para $12 \%$ na $9^{a}$ edição. O Lockdown atingiu $6 \%$ na $4^{\text {a }}$ edição e foi diminuindo até $1 \%$ na $9^{a}$ edição. As empresas que declararam estar em processo de reabertura/aberto, partiram de $35 \%$ na $4^{\text {a }}$ edição, atingindo $86 \%$ na $8^{\text {a }}$ edição, diminuindo para $80 \%$ na 9a edição. Já, nas empresas que declararam não ter restrições, o movimento partiu de $2 \%$ na 4⿳亠丷a edição, e atingiu $8 \%$ na 9 a edição. As maiores variações ocorreram entre as empresas que se declararam estar em municípios que aderiram à Quarentena, apresentando redução de expressivos $45 \%$, enquanto, num movimento contrário, as empresas que declararam estar em municípios que aderiram ao Lockdown, apresentaram um aumento de $45 \%$. 


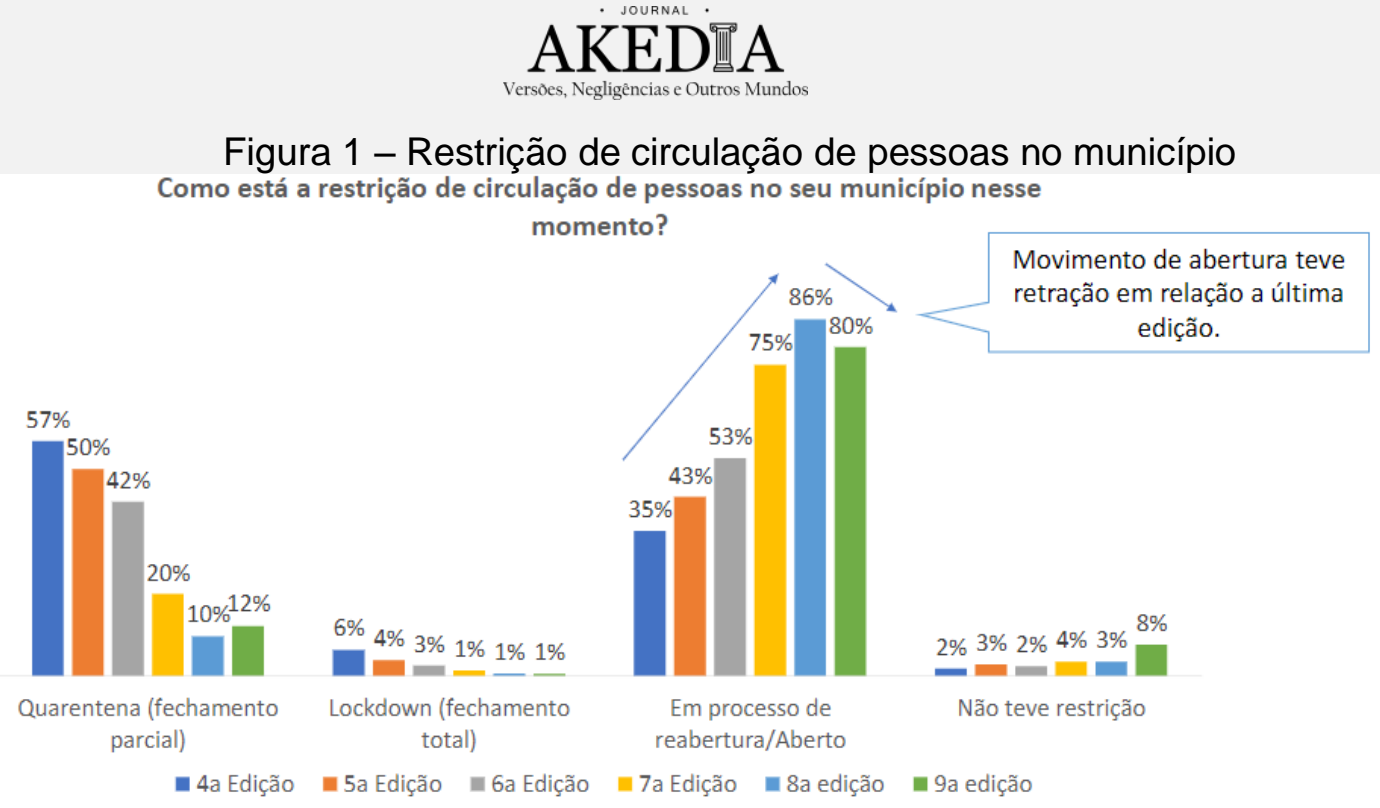

Fonte: SEBRAE; FGV, 2020

Outra questão que a pesquisa apresentou, foi sobre o quanto a mudança no horário de funcionamento por conta da crise (Figura 2). A pesquisa revelou em sua $2^{a}$ edição, que $38 \%$ das empresas respondentes estavam operando, sendo que $7 \%$ funcionavam da mesma forma que antes da crise, enquanto que $31 \%$ funcionavam com mudanças por causa da crise.

Já, na 9a edição, $86 \%$ das empresas revelaram que estão operando, sendo que $19 \%$ funcionam da esma forma que antes da crise e $67 \%$ estão funcionando com mudanças por conta da crise.

Dentre as empresas que estão com o funcionamento temporariamente interrompido, de $59 \%$ na $2^{\circ}$ edição, diminuiu para $11 \%$ na $9^{a}$ edição, o que demostra que as empresas então retomando seu funcionamento, mesmo que com mudanças por conta da crise.

Figura 2 - Mudança de funcionamento por conta da crise Sua empresa mudou o funcionamento com a crise?

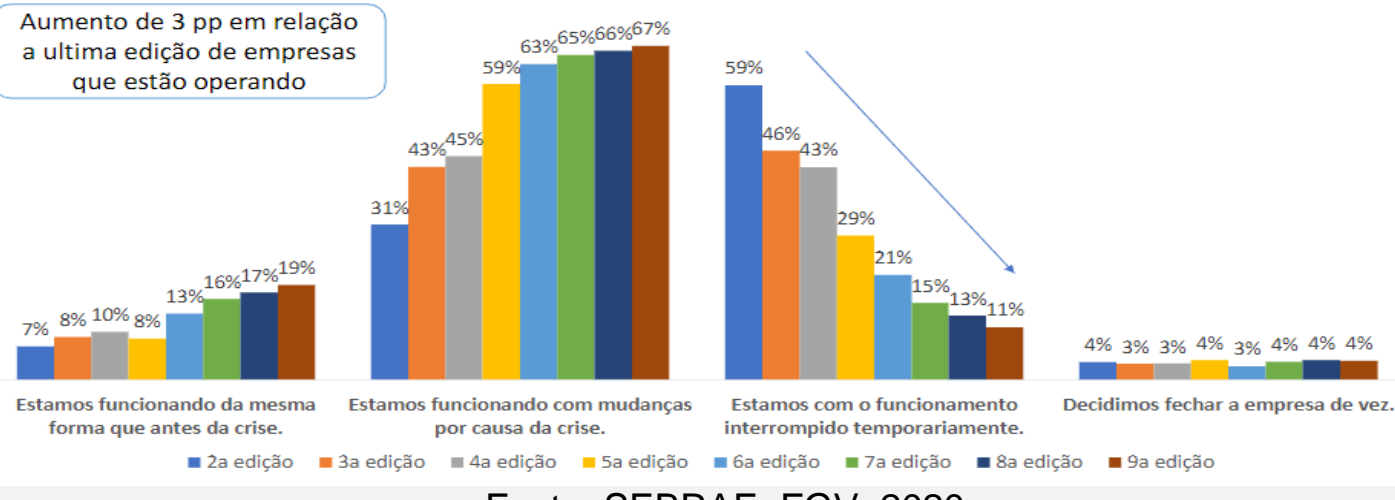

Fonte: SEBRAE; FGV, 2020 


\section{AKED芭A}

A crise sanitária e econômica vem provocando transformações no ambiente empresarial. Podemos observar que 04 em cada 10 empresas inovaram durante a crise (Figura 3). Isto mostra que, desde o início da crise, as empresas lançaram ou começaram a comercializar novos produtos ou serviços, sendo $39 \%$ registrados na $8^{\circ}$ edição e $43 \%$ na $9^{\text {a }}$ edição da pesquisa.

Ou seja, a mudança provocada pela crise afetou não apenas 0 funcionamento das empresas, mas também alterou o mix de produtos e serviços existentes antes do início da Pandemia.

Figura 3 - Inovação em produtos e/ou serviços após inicio da crise

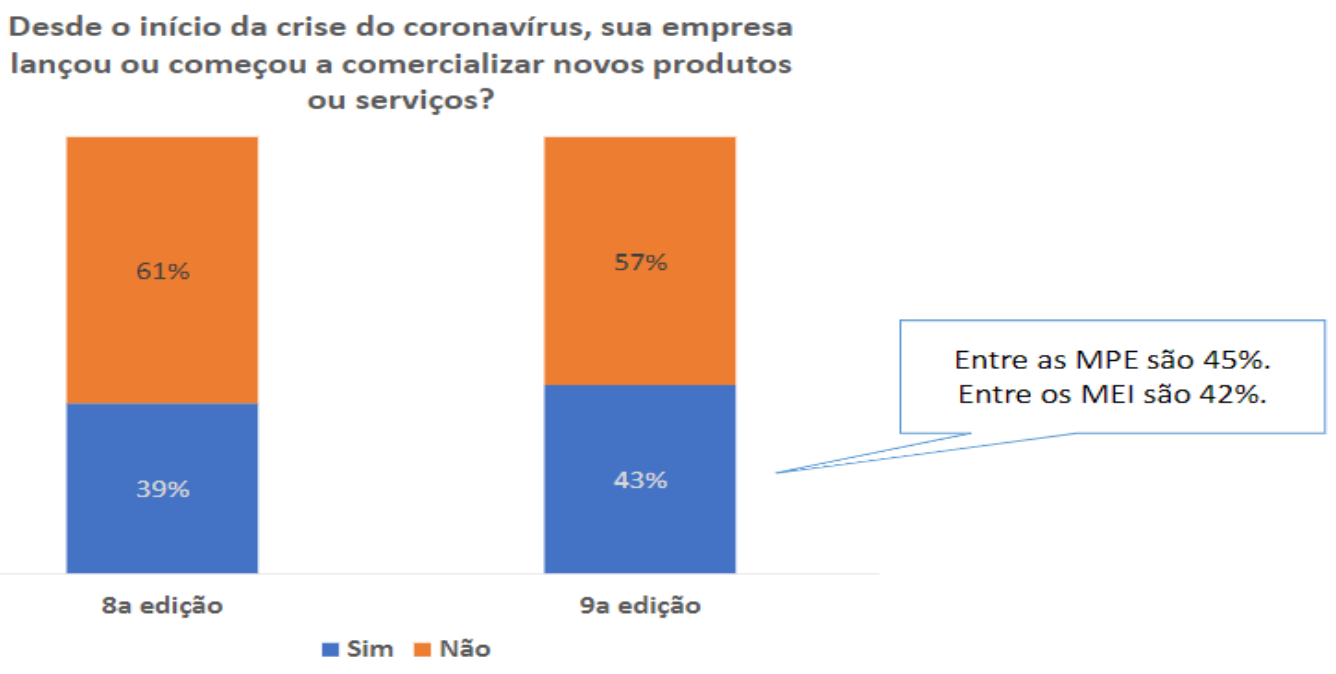

Fonte: SEBRAE; FGV, 2020

Quando questionados sobre quais canais de vendas as empresas têm utilizado, WhatsApp e Instagram atingiram índices superiores a $84 \%$ e $49 \%$ respectivamente (Figura 4).

Facebook, site próprio e aplicativos de entregas ou serviços a domicílio (iFood, Uber Eats, Rappi, GetNinjas e outros), Mercado Livre e OLX também são soluções utilizadas que ajudam as empresas a realizar vendas neste período da Pandemia, especialmente num momento em que 0 isolamento social minimiza a circulação e impede a aglomeração de pessoas, alterando o funcionamento empresarial. 


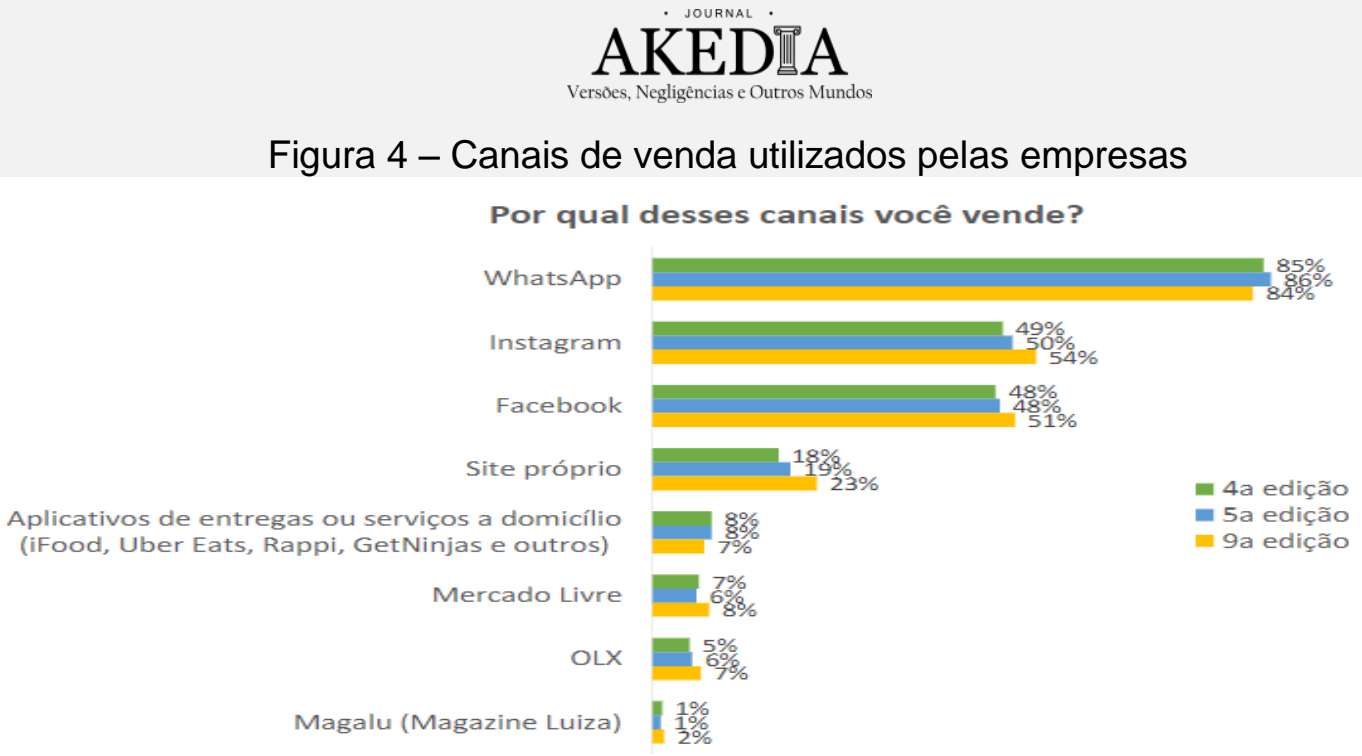

Fonte: SEBRAE; FGV, 2020

No levantamento de dados sobre as empresas que estão presentes nos aplicativos iFood e UaiRango, 111 empresas foram identificadas, das quais 87 também mantém perfis no Instagram (Figura 5).

Figura 5 - Número de empresas do setor de serviços de alimentação com perfis no iFood, UaiRango e Instagram

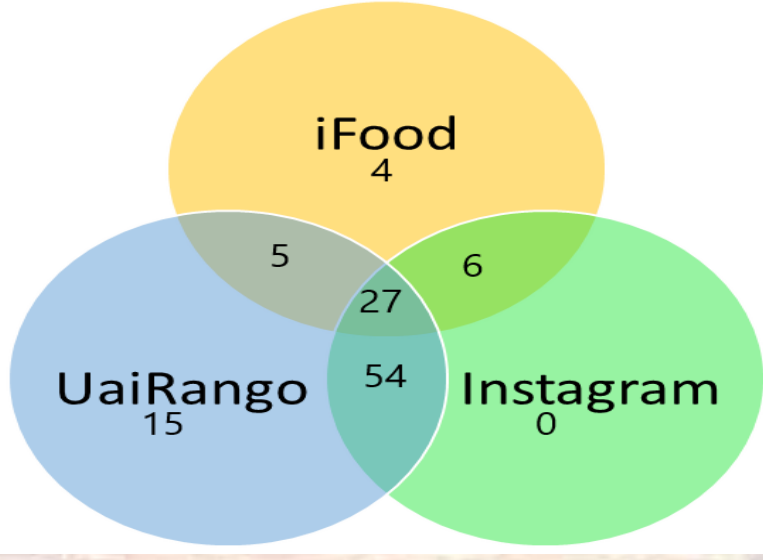

Fonte: Elaborado pelos autores

Em números absolutos, 101 empresas utilizam o UaiRango (90,99\%), seguido de 87 empresas que utilizam o Instagram (78,38\%) e 42 empresas que utilizam o iFood (37,84\%). Vale destacar, que uma empresa pode utilizar mais de um destes canais ao mesmo tempo. Assim, detectou-se que 27 empresas analisadas utilizam ao mesmo tempo o iFood, UaiRango e Instagram, correspondendo a $24,32 \%$.

Juntam-se a estas empresas, aquelas que utilizam apenas o UaiRango e o Instagram, que totalizam 54 empresas, correspondendo a 48,64\%; 6 
empresas utilizam apenas o iFood e o Instagram, o que perfaz a $5,40 \%$ do total. Além disso, há 05 empresas utilizam apenas o iFood e o UaiRango, o que equivale a $4,50 \%$ do montante. Restaram 15 empresas que utilizam somente 0 UaiRango (13,51\%) e 04 empresas que utilizam somente o iFood (3,60\%).

Como o levantamento partiu das empresas que utilizam o iFood ou 0 UaiRango, não foi possível identificar as empresas do setor de serviços de alimentação, do município de Frutal - MG, que possuem perfil apenas no Instagram, devido à dificuldade técnica de se identificarem elementos que poderiam fazer parte deste levantamento, sem deixar de considerar um número significativo de empresas que se encaixariam no perfil investigado. Os aplicativos iFood e UaiRango permitem visualizar todas as empresas do setor e do município em questão, facilitando a busca.

Este resultado vem de encontro com o cenário apresentado pela pesquisa realizada pela parceria entre SEBRAE e FGV, a qual demonstra que 7 em cada 10 empresas estão realizando vendas com a utilização da internet (Figura 6). Percebe-se um aumento significativo, desde a $4^{\text {a }}$ edição da pesquisa até a edição atual, passando de $59 \%$ para $70 \%$ o percentual de empresas que utilizam WhatsApp, Facebook, Instagram, entre outros.

Figura 6 - Utilização de redes sociais, aplicativos ou internet

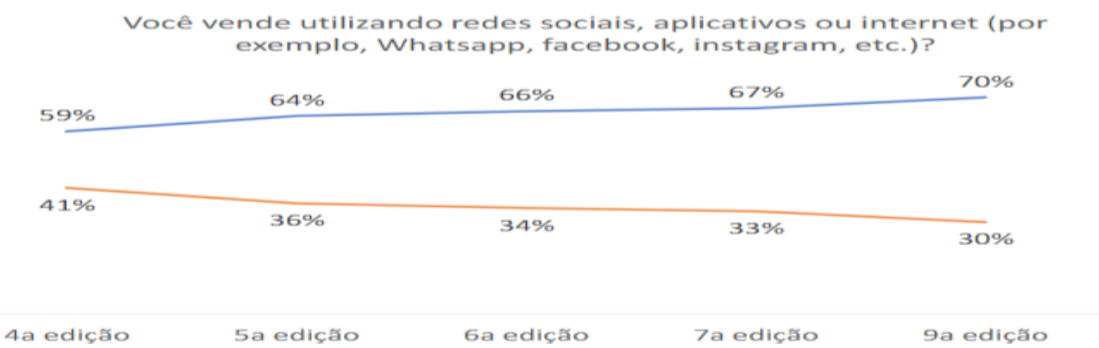

Fonte: SEBRAE; FGV, 2020

\section{FATURAMENTO E CUSTOS}

Ao acompanhar como o negócio está sendo afetado, até o momento, pela Pandemia da COVID-19, em termos de faturamento mensal, percebe-se que a proporção de empresas com queda no faturamento vem diminuindo (Figura 7). 


\section{AKED』A}

A referida questão apresentou como alternativas de respostas, que o faturamento "aumentou", "diminuiu", "permaneceu igual" ou "não sabe ainda"/ "não quis responder".

$\mathrm{Na} 1^{\underline{a}}$ edição, $89 \%$ das empresas respondentes declararam que o seu faturamento diminuiu com a Pandemia, caindo para $73 \%$ na $9^{\circ}$ edição. Ainda, nesta 9a edição, entre as MPE (Médias e Pequenas Empresa), 69\% declararam que seu faturamento diminuiu $e$, entre os MEI (Microempreendedores Individuais), temos $76 \%$ nesta mesma condição.

Observa-se também que houve um aumento das empresas que declararam que seu faturamento aumentou, passando de $3 \%$ na $1^{\text {a }}$ edição para $11 \%$ na 9a edição, na mesma proporção dos que responderam que "não sabem ainda" ou "não quiseram responder", cujos resultados apresentados partem de $3 \%$ na $1^{\mathrm{a}}$ edição para $12 \%$ na $9^{\underline{a}}$ edição.

Entre as empresas que declararam que seu faturamento permaneceu igual, os resultados, ao longo das edições, não apresentaram alterações significativas, tendo atingido $5 \%$ na 1 a edição e $4 \%$ na 9 a edição.

Figura 7 - Alterações no faturamento mensal por conta da Pandemia Como o seu negócio está sendo afetado, até este momento, pelo CORONAVírUS em termos de faturamento mensal?

$89 \%$ $89 \%$ $84 \%$ $81 \%$

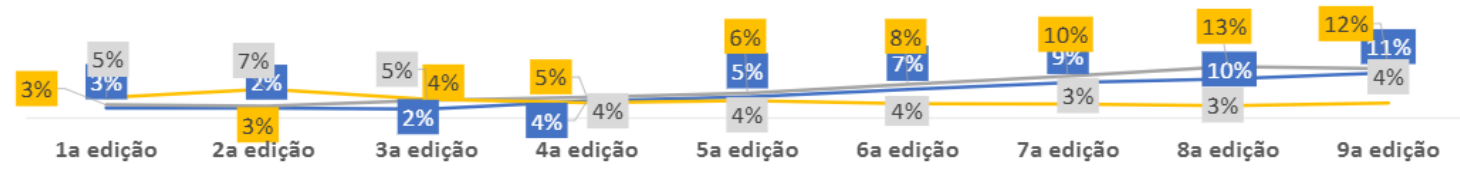

-Aumentou -Diminuiu -Permaneceu igual —Não sabe ainda/não quis responder

Fonte: SEBRAE; FGV, 2020

Quanto ao impacto médio no faturamento das empresas (Figura 8), a $1^{\text {a }}$ edição registrou uma queda de $64 \%$, aumentando para $70 \%$ de queda na $2^{\text {a }}$ edição. A 8 edição registrou o menor índice de queda, atingindo $36 \%$, enquanto a $9^{a}$ edição apresentou uma leve retraída, chegando a $39 \%$ de queda no faturamento. 


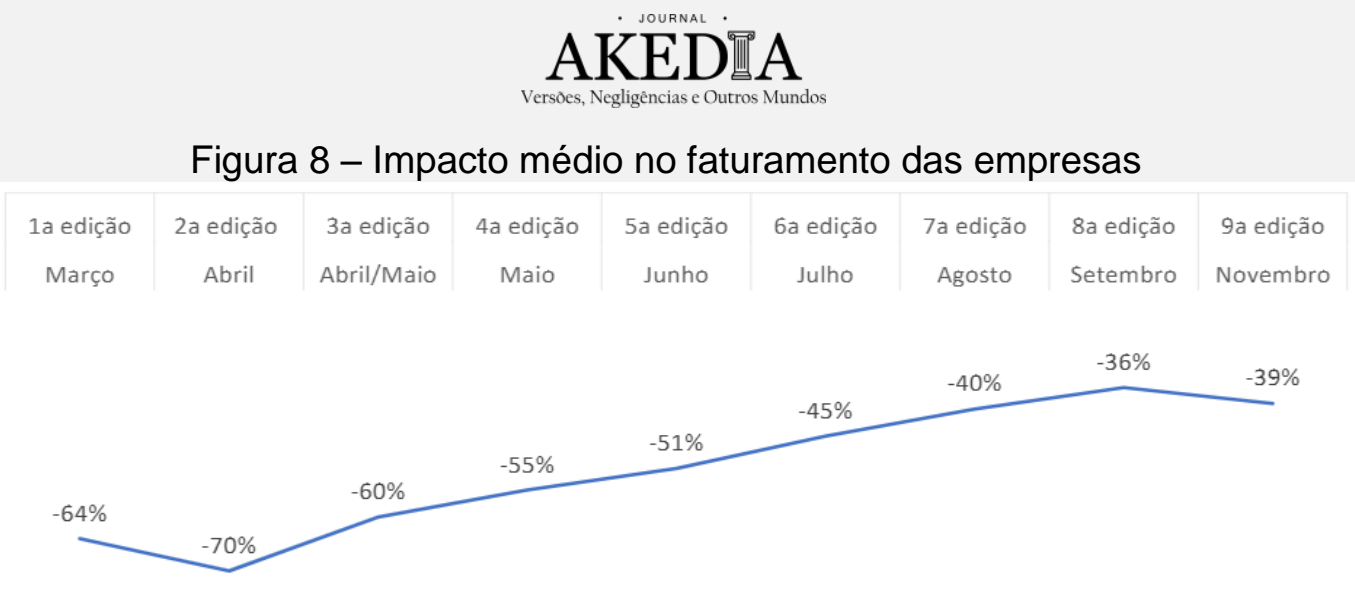

Fonte: SEBRAE; FGV, 2020

Quando questionados sobre a pretensão de realizar algum investimento em 2021 (Figura 9), 63\% das empresas responderam que farão algum investimento, o que mostra uma visão otimista em relação ao cenário econômico. Observa-se que $10 \%$ das empresas indicam que farão reservas de emergência e, por fim, $27 \%$ das empresas afirmam não terem condições de realizarem nenhum investimento em 2021.

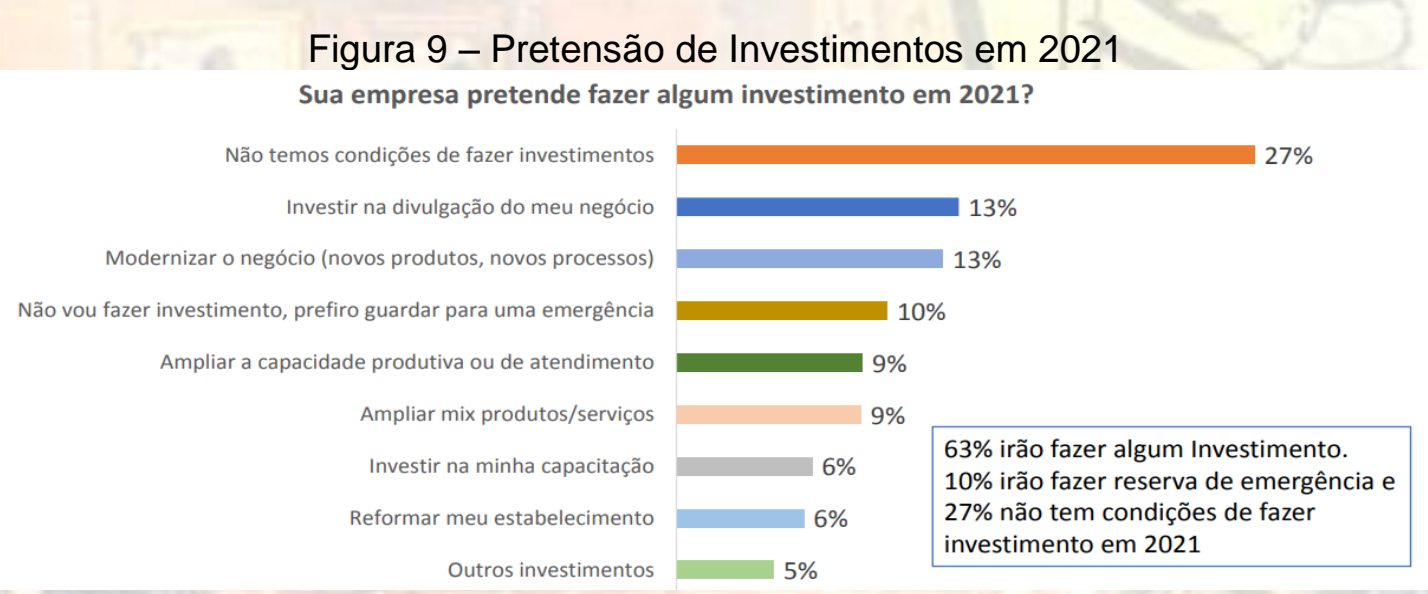

Fonte: SEBRAE; FGV, 2020

Embora cerca de uma entre cada quatro empresas afirmassem que não possuem condições de realizar investimentos em 2021, as outras empresas, com uma visão mais otimista, revelam que pretendem investir na divulgação do negócio, modernizar a carteira de produtos ou ciclo de processos operacionais, ampliar a capacidade produtiva ou de atendimento, ampliar o mix de ofertas ou serviços prestados, investir na capacitação do empresário e dos funcionários e reformar o estabelecimento, além de outros tipos de investimentos. Este movimento de investir no próprio negócio, aquece a economia e amplia as possibilidades de retorno sobre o investimento. 


\section{AKED远A \\ MEDIDAS DO GOVERNO RELACIONADAS À RENDA E AO IMPACTO SOBRE OS TRABALHADORES BRASILEIROS}

Quando há uma disfuncionalidade nos mercados, o papel do Estado é fundamental para evitar a desorganização total da economia. Políticas monetária e fiscal agressivas e não convencionais foram utilizadas em escala muito maior em 2020 do que durante a crise de 2008. Naquela ocasião, a crise era financeira e concentrada nos países desenvolvidos, com baixa percepção do fenômeno pelos países em desenvolvimento. No caso da Pandemia atual, a crise global e recursos estão sendo canalizados para a saúde, para a sobrevida de empresas e manutenção do emprego, a fim de garantir uma base para a retomada posterior da economia (SILBER, 2020).

Conforme analisado e criticado por especialistas, o Governo Federal não possui um plano de ações devidamente organizado e articulado para amenizar os efeitos da Pandemia sobre as atividades econômicas. Outras demais pautas, referentes ao mercado de trabalho brasileiro, as medidas adotadas também podem ser consideradas prejudiciais, pois, ao invés de buscar preservar os empregos e os salários dos trabalhadores, elas operam exatamente no sentido oposto, ou seja, para estimular o desemprego e rebaixar os salários (MATTEI; HEINEN, 2020):

As intenções do governo nesse sentido já ficaram claras, pelo menos desde 22 de março deste ano, quando o governo editou a Medida Provisória (MP) no 927, que além de desconfigurar o que restou da CLT, passava a permitir a suspensão dos contratos de trabalho por quatro meses sem pagamento dos salários. Tal MP foi cancelada, em parte, no dia seguinte, em ato no qual o Ministro da Economia confessou que "assinou a MP sem ler", enquanto o Presidente da República tentou se explicar afirmando que "houve um erro na redação" (MATTEI; HEINEN, 2020, p. 657).

Seguindo as mesmas pretensões, tal medida foi reeditada na data do dia $1^{\circ}$ de abril de 2020, como MP no 936, mas, agora, com a reconhecida nomeação de um Programa Emergencial de Manutenção de Emprego e Renda.

A principal alteração promovida pela nova MP (Medida Provisória) em relação à medida anterior foi a permissão da redução da jornada de trabalho com percentuais que podem ser, a princípio, de $25 \%, 50 \%$ ou $70 \%$, com 


\section{AKEDTA}

correspondente desconto nos salários, além da autorização para a suspensão do contrato de trabalho - uma redução de $100 \%$ da jornada e do salário (MATTEI; HEINEN, 2020).

Conforme apresentam Mattei e Heinen (2020), em relação ao caso da redução das jornadas, a medida implementada tem duração de até 90 dias, sendo que o consequente corte nos salários é proporcionalmente compensado, de acordo com o valor do seguro-desemprego, ao qual o trabalhador teria direito caso fosse demitido. Particularmente, no caso em que esse acordo for firmado em negociação coletiva, o percentual poderá ser diferente dos mencionados acima, todavia, o benefício ainda será limitado a essas frações estabelecidas.

Caso a opção seja pela suspensão do contrato, Mattei e Heinen (2020) afirmam que a medida é válida por até 60 dias, sendo que o trabalhador deverá receber o valor integral previsto pelo seguro-desemprego. Em ambos os casos, a MP prevê estabilidade no emprego até o dobro do período de redução, ou seja, se a redução/suspensão perdurar por dois meses, o empregado não poderá ser demitido sem justa causa nos dois meses seguintes. O texto também prevê um valor fixo de $\mathrm{R} \$ 600,00$ aos trabalhadores intermitentes formalizados, de forma semelhante ao auxílio emergencial aos informais.

As regras de funcionamento do programa são distintas, em função do faturamento das empresas, conforme apresentam Mattei e Heinen (2020). Assim, as empresas que adotarem a suspensão de contratos ou a redução de jornadas e tiverem faturamento de até $R \$ 4,8$ milhões não precisarão fornecer nenhuma compensação ao salário, que será coberto com $100 \%$ do valor do seguro-desemprego, de acordo com o salário-hora contratual. Já, para empresas com faturamento acima de $\mathrm{R} \$ 4,8$ milhões, o seguro cobrirá $70 \%$ do valor previsto.

De acordo com Mattei e Heinen (2020), os acordos entre empregadores e empregados poderão ser firmados, obedecendo aos seguintes critérios: quando a redução de jornada e de salário for de até $25 \%$, o acordo pode ser individual entre as partes, independentemente do nível salarial.

Nos demais casos (redução de $50 \%, 70 \%$ ou suspensão de contrato), acordos individuais somente poderão ser celebrados com trabalhadores que 
recebem menos de $R \$ 3.135,00$ ou mais de $R \$ 12.202,12$. Trabalhadores com salários entre esses dois valores somente poderão fazer acordos de redução de jornada e de salário mediante convenção coletiva com participação do sindicato da categoria.

A MP 936, segundo Mattei e Heinen (2020), também alterou diversas regras da legislação trabalhista que estavam em vigor até o momento, sempre com o objetivo oficial de "preservar empregos".

Assumindo que acordos individuais celebrados neste período de calamidade pública prevalecerão sobre os instrumentos legais em vigor (acordado se sobrepondo ao legislado), permitiu-se: o trabalho remoto (teletrabalho, home-office); a concessão de férias coletivas com aviso antecedente de apenas 48 horas; a antecipação de férias individuais e de feriados; o regime especial de compensação (banco de horas); e a suspensão de exigências administrativas em segurança e saúde do trabalhador.

Mattei e Heinen (2020) apresentam que a equipe econômica do governo previa que 24,5 milhões trabalhadores com carteira de trabalho assinada firmarão acordos de redução de salário ou suspensão de contratos de trabalho, com base na MP 936, até o fim do período de calamidade pública, em 31 de dezembro.

Segundo a Secretaria Especial de Previdência e Trabalho do Ministério da Economia, até o dia 23 de abril de 2020, já haviam sido registrados 3,5 milhões de acordos (SEPRT apud o GLOBO, 2020). A maior parte desse montante ( $58,3 \%$ ou cerca de 2 milhões de registros) é de trabalhadores que tiveram seus contratos suspensos, conforme indicado na Figura 9.

Figura 9 - Distribuição dos acordos firmados pela MP 936 por grau de redução da jornada $\left(\%, 1^{\circ}\right.$ a 23 de abril de 2020$)$

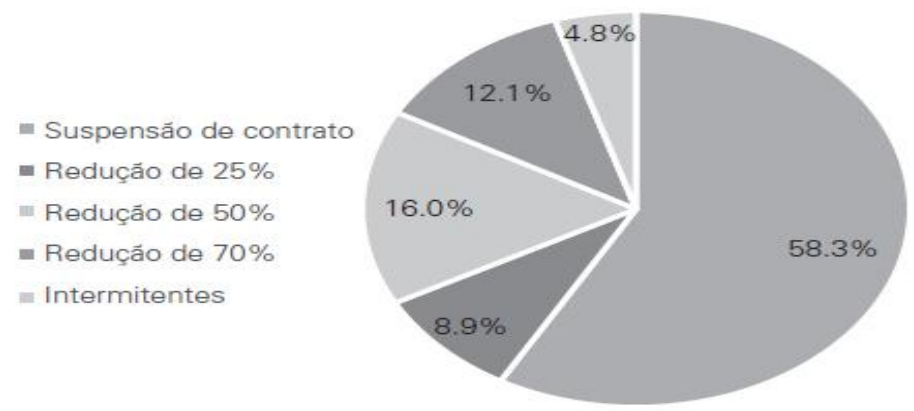

Fonte: Mattei e Hansei, 2020 
O Auxílio Emergencial foi aprovado pelo Congresso Nacional e consolidado na Lei no 13.982, de 28 de março de 2020, que foi regulamentada pelo Decreto o 10.316 , de 07 de abril de 2020, dia em que começaram os primeiros pagamentos. Desde então, acumulam-se inúmeras reclamações de famílias que não conseguiram acessar ao benefício. Para se ter uma ligeira noção da dimensão desse problema, basta registrar que técnicos da área social estimam entre 15 e 30 milhões o número de trabalhadores informais fora do "Cadúnico" do Governo Federal.

\section{CONSIDERAÇÕES FINAIS}

É contraditória a imagem representada pelo Governo Federal, se comparada com a paisagem retratada por algumas instituições internacionais: enquanto, aqui, se pensa que a Pandemia logo passará, de lá, chegam notícias de que os efeitos econômicos da COVID-19 não terão curta duração.

A Pandemia deflagrou e desenvolveu uma crise em escala, que deve reverberar por muitos anos. No Brasil, essa crise será o bode expiatório adotado pelo governo, que cinicamente se defenderá, dizendo que a economia e o mercado de trabalho vinham bem até o início de 2020.

Conforme enfatizado nas análises, a situação já era ruim, mesmo antes desta nova crise, porém, piorou significativamente para a vertente das microempresas, considerando o baixo faturamento e entradas, além do número de desempregados.

Os impactos no país tendem a ser ainda mais dramáticos. O Brasil iniciou 2020 com uma taxa de desemprego acima de 11\%. Diante dos desenlaces da Pandemia sobre a estrutura produtiva e também sobre o nível de consumo, não será nada surpreendente se essa taxa atingir os $20 \%$ ao final do ano, o que conflagraria um cenário em que um em cada cinco brasileiros que necessitam trabalhar não encontraria emprego.

No entanto, o grau de formalização das ocupações no Brasil vem caindo continuamente, desde 2015, com destaque para a perda dos empregos no ramo industrial. Sem o dinamismo desse setor, uma massa de trabalhadores foi se deslocando para setores de menor produtividade e menores salários, 


\section{AKED』A}

especialmente no comércio e serviços em geral, os quais serviram como válvula de escape à deterioração e queda do emprego formal.

Com isso, cerca da metade dos postos de trabalho do início de 2020 eram ocupações informais. Essa é a parcela dos trabalhadores brasileiros que vive sob o risco de ter ficado imediatamente sem renda na nova conjuntura. Nesse sentido, a paralisação das atividades, a desassistência do Estado e a crise econômica que já está em curso, em âmbito global, tenderão a acirrar ainda mais os problemas do mercado de trabalho nacional, não só pelas condições em que os trabalhadores informais se encontram, mas, também, porque essas ocupações deixarão de ser uma alternativa àqueles que forem sendo demitidos de empregos formais. Esses são, na essência, os problemas de um mercado de trabalho "flexível", condição tanto apregoada pelo ideário econômico neoliberal.

Neste cenário de profundas dificuldades, é imperioso afirmar que as medidas anunciadas pelo Governo Federal - como no caso da MP 936, que autorizou acordos individuais (particularmente entre os trabalhadores com menores remunerações e que recebem até $R \$ 3.135)$; a suspensão de contratos (com baixos custos ao empregador); e, a redução parcial de salários, levando a uma queda de até 10,7 bilhões na massa salarial - na verdade acabam estimulando e/ou facilitando o desemprego, ao mesmo tempo em que não oferecem nenhum mecanismo efetivo que seja capaz de garantir a estabilidade no emprego por um período mais longo do que alguns meses.

Ao lado disso, a própria Lei do Auxílio Emergencial, além de ser insuficiente - visto que mal cobre um terço dos rendimentos médios dos trabalhadores informais - não é um mecanismo de renda básica, tal como vendo sendo implementado em outros países.

Em síntese, é possível afirmar que as medidas adotadas até o presente momento não serão capazes de conter a abrupta queda da renda da classe trabalhadora e conseguir restabelecer a economia brasileira. Ao contrário, as medidas adotadas parecem ir mais ao sentido de tornar o mercado de trabalho nacional instável, por tempo indeterminado, comparado às medidas em que se garantam um nível de emprego adequado e um patamar de renda suficiente para atender às necessidades básicas da população. 
Com isso, há uma possibilidade de quedas sequenciais na demanda, o que contribuirá para que, ao longo do próximo período, seja retroalimentado o desemprego e elevada a degradação das condições sociais de reprodução da classe trabalhadora. No sentido inverso das medidas que vêm sendo adotadas, os próximos períodos irão mostrar uma vez mais que o problema crucial não é o custo do trabalho, mas a incapacidade da própria dinâmica econômica em gerar novos empregos com qualidade e em quantidades suficientes para atender todos os trabalhadores do país, que atualmente se encontram efetivamente fora do mercado de trabalho organizado.

A respeito das microempresas, é possível ressaltar que, apesar da crise, muitos empresários conseguiram implementar estratégias para que os empreendimentos continuassem funcionando. Pelo estudo, é possível observar como as formas de atuar dos pequenos empreendedores estão evoluindo neste momento. Entre as empresas que continuaram funcionando, 41,9\% realizam agora apenas entregas via atendimento online. Outros $41,2 \%$ estão trabalhando com horário reduzido, enquanto $21,6 \%$ estão realizando trabalho remoto.

Outra maneira destacada nas análises, também encontrada pelos pequenos empresários, para não interromperem o funcionamento, foi a implementação de um rodízio de funcionários. Essa opção foi adotada por $15,3 \%$ das empresas. Já, a implementação de um sistema de drive thru foi a alternativa para $5,9 \%$ delas.

Em suma, o mercado tem buscado se sustentar de forma autônoma, sem intervenções por parte do Governo Federal ou outras medidas de apoio governamentais para evitar desfechos da Pandemia e da crise econômica mais complicados ou irreversíveis. 


\section{REFERÊNCIAS}

BRASIL. Banco Central do Brasil. Focus - Relatório de Mercado. 24 ago. 2020a. Disponível em: <https://www.bcb.gov.br/publicacoes/focus>. [ Links ]

BRASIL. Ministério da Economia. Governo destaca papel da Micro e Pequena Empresa para a economia do país. 05 out 2020b. Disponível em: https://www.gov.br/economia/pt-br/assuntos/noticias/2020/outubro/governodestaca-papel-da-micro-e-pequena-empresa-para-a-economia-do-pais. Acesso em: 05 fev. 2021.

MOTA, C. V. Os setores que ainda estão contratando em meio à pandemia. REVISTA ÉPOCA, 13 abr. 2020. Disponível em: https://epoca.globo.com/economia/os-setores-que-ainda-estao-contratando-emmeio-pandemia-1-24367725. Acesso em: 12 dez. 2020.

O GLOBO. MP 936: acordos de redução de salário e suspensão de contrato de trabalho já chegam a 3,5 milhões. 23 abr. 2020. Disponível em: www.oglobo.globo.com/economia/mp-936-acordos-de-reducao-de-salariosuspensao-de-contrato-de-trabalho-ja-chegam-35-milhoes-1-24389615.

PINHEIRO, Roberto Meireles et. al. Comportamento do consumidor e pesquisa de mercado. 3 ed. Rio de Janeiro: Editora FGV, 2006.

PRODANOV, C. C.; FREITAS, E. C. Metodologia do trabalho científico: métodos e técnicas de pesquisa e do trabalho acadêmico. 2. ed. Novo Hamburgo: FEEVALE, 2013.

SEBRAE. O impacto da pandemia de coronavírus nos Pequenos Negócios. Nov. de 2020. Disponível em: www.fgvprojetos/impacto_coronavirus_nas_ mpe_9aedicao_diretoria_v3. Acesso em: 05 de fevereiro de 2020.

SEBRAE. Pequenos negócios já representam 30\% do Produto Interno Bruto. 08 abr. 2020b. Disponível em: http://www.agenciasebrae.com.br/sites/asn/uf/ NA/pequenos-negocios-ja-representam-30-do-produto-interno-bruto-dopais,7b965c911da51710VgnVCM1000004c00210aRCRD. Acesso em: 06 fev. 2021.

SEBRAE. Confira as diferenças entre micro empresa, pequena empresa e MEI. 04 fev. 2021. Disponível em: https://www.sebrae.com.br/sites/PortalSebrae/ artigos/entenda-as-diferencas-entre-microempresa-pequena-empresa-e-

mei,03f5438af1c92410VgnVCM100000b272010aRCRD. Acesso em 05 fev. 2021.

SEBRAE; FGV. Atualização de estudo sobre participação de Micro e Pequenas Empresas na economia nacional. Mar. 2020. Disponível em: https://datasebrae.com.br/wp-content/uploads/2020/04/Relat\%C3\%B3rioParticipa\%C3\%A7\%C3\%A3o-mpe-pib-Na.pdf. Acesso em: 06 fev. 2021.

SILBER, S. A fragilidade econômica e financeira na pandemia do SARSCOVID-19. Estudos Avançados. São Paulo, vol. 34, n. 100, p. 107-115, dez. 2020.

em: http://www.scielo.br/scielo.php?script=sci_arttext\&pid=S0103$40142020000300107 \&$ Ing=en\&nrm=iso. Acesso em 02 fev. 2021. 